\title{
Aplikasi sistem perhiasan 2in1 dengan tema Arabian Night
}

\author{
Ratu Fita Rahma Auliya‘Ullah, Ellya Zulaikha, Ari Dwi Krisbianto \\ Departemen Desain Produk, Institut Teknologi Sepuluh Nopember, Surabaya, Indonesia
}

\begin{abstract}
Jewelry in general is a fashion item that is favored because of its uniqueness, beauty, and ability to become one of the investment objects. Various types, materials, and models of jewelry can affect the value of the jewelry. One of them is gold jewelry. Gold jewelry is not only preferred because of the visual aesthetics of the style and model of the jewelery, but also because the weight of gram values in each design has a stable investment price, and can also be an identity that reflects the user's lifestyle and is the most considered factor when choosing jewelry. In the value of use, some jewelry has its own value for a culture and is often worn for traditional events or certain holidays, such as Eid or weddings. Innovations in jewelry designs are needed to produce new products that can meet market opportunities, one of which is multiform jewelry design, where one model of jewelry can be worn in two or more ways. This study focuses on jewelry with the concept of 2in1 which takes the theme of Arabian Night on the basis of cooperation with one of the largest gold companies in Indonesia to issue gold jewelery designs that will be produced and accepted by the public.
\end{abstract}

Key words: jewelry, 2in1, investment, lifestyle, gold, market opportunities

\begin{abstract}
Abstrak
Perhiasan pada umumnya adalah item fashion yang digemari karena keunikan, keindahan, dan kemampuannya menjadi salah satu benda investasi. Berbagai jenis, bahan, dan model perhiasan dapat mempengaruhi nilai dari perhiasan tersebut. Salah satunya adalah perhiasan berbahan emas. Perhiasan emas bukan hanya disukai karena estetika visual dari corak dan model perhiasan tersebut namun juga karena berat nilai gram dalam setiap desain yang mempunyai harga investasi yang stabil, dan juga dapat menjadi identitas yang mencerminkan gaya hidup pengguna sekaligus menjadi faktor yang paling dipertimbangkan saat memilih perhiasan. Dalam nilai penggunaan, beberapa perhiasan mempunyai nilai tersendiri untuk suatu budaya dan sering dikenakan untuk acara adat atau hari raya tertentu atau acara pernikahan. Inovasi pada suatu desain perhiasan diperlukan untuk menghasilkan produk baru yang dapat memenuhi peluang pasar, salah satunya adalah desain perhiasan multiform, dimana satu model perhiasan dapat dikenakan dengan dua cara atau lebih. Penelitian ini berfokus pada perhiasan dengan konsep 2in1 yang mengambil tema Arabian Night atas dasar kerjasama dengan salah satu perusahaan emas terbesar di Indonesia untuk mengeluarkan desain perhiasan emas yang akan diproduksi dan dapat diterima oleh masyarakat.
\end{abstract}

Kata kunci: perhiasan, 2in1, investasi, gaya hidup, emas, peluang pasar

\section{Pendahuluan}

Awal mulanya perhiasan merupakan fungsi dari suatu objek, khususnya yang digunakan untuk menghias pakaian seperti peniti, gesper dan pin (Clarke, 2010). Perhiasan (anting, gelang, cincin, dan gelang kaki) dewasa ini bukan hanya sebagai sarana untuk membuat penampilan lebih menarik namun juga sebagai bentuk ekspresi integral, kekayaan dan status sosial. Setiap hiasan yang dikenakan oleh perempuan bisa menggambarkan siapa perempuan itu sebenarnya (Masmadia, 2018).
Perhiasan dapat dibuat dengan berbagai bahan, teknik, dan model. Emas merupakan salah satu bahan perhiasan yang memiliki sifat yang tidak mudah rusak, tahan lama, dan oksidasi, merupakan komoditi yang langka, memiliki nilai yang tetap dan harga perolehan yang terus meningkat. Badan Pusat Statistik (BPS) Provinsi Jawa Timur (Jatim) mencatat nilai ekspor provinsi ini sepanjang 2017 mengalami peningkatan 3,49 \% dibandingkan tahun sebelumnya. Salah satu penyumbang terbesar nilai ekspor tersebut adalah perhiasan logam mulia dengan nilai USD 2,16 miliar atau 11,01\% dari total

\footnotetext{
* Corresponding author; e-mail: ratuullah@gmail.com
} 
ekspor Jawa Timur. Tingkat penjualan emas akan meningkat khususnya mendekati Hari Raya Idul Fitri. Menurut Asosiasi Ritel Indonesia (APRINDO), menjelang Idul Fitri penjualan produk pakaian jadi mengalami peningkatan yang drastis yaitu antara 200\% hingga 300\%. Selain itu, menurut APRINDO, pada momen-momen menjelang Idul Fitri jumlah pengunjung mall mengalami peningkatan sampai sebesar $100 \%$.

Selain memiliki nilai investasi jangka panjang, emas juga memiliki nilai estetika unik. Emas dapat diolah menjadi beragam bentuk perhiasan yang dipandang sebagai salah satu indikator akan posisi status identitas pengguna tersebut dalam suatu masyarakat. Perhiasan bukan hanya sebagai sarana untuk membuat penampilan lebih menarik namun juga sebagai bentuk ekspresi integral, kekayaan dan status sosial. Memahami bahwa perhiasan dapat menunjukkan status sosial seseorang di dalam masyarakat, maka tidak mengherankan jika menggunakan perhiasan kini menjadi gaya hidup masyarakat (Herdiana \& Santosa, 2018). Perhiasan yang selain untuk dipakai dapat mencerminkan ekspresi dan karakter individunya (Lignel, 2008).

Model suatu perhiasan yang disesuaikan dengan gaya hidup pengguna dewasa ini semakin berkembang dan memunculkan berbagai inovasi. Berbedanya tujuan penggunaan perhiasan bagi tiap pribadi menyebabkan banyaknya variasi jenis dan gaya perhiasan (Flockinger, 2010). Salah satumya adalah inovasi perhiasan 2in1 (two in one). Two in one adalah istilah popular Bahasa Inggris yang berasal dari kalimat make the two into one yang berarti membuat yang dua menjadi satu (kamuslengkap.com, 2018). Dengan kata lain, dua model perhiasan menjadi satu atau sebaliknya. Perhiasan dengan sistem 2in1 menguntungkan pengguna karena dengan membeli perhiasan dengan gram atau berat yang sama pengguna dapat menggunakan perhiasan tersebut dengan dua cara.

\section{Bahan dan Metode}

Untuk menghasilkan produk yang optimal dari sisi desain, diperlukan tahapan-tahapan proses desain. Paling tidak ada 5 proses desain yang dilakukan yaitu:

a. Discovery, adalah proses diskusi dan brief desain dengan perusahaan terkait tentang peluang pasar yang dapat diekspos dan sistematika proses dalam menghasilkan sebuah desain perhiasan yang dapat diproduksi. b. Survey, adalah pengumpulan informasi dari orang-orang tentang presepsi, pikiran, pikiran, perilaku, perasaan, dan sikap mereka terhadap suatu fenomena dengan membuat user diary terhadap target pengguna dan deep interview dengan orang yang ahli dibidang perhiasan.

c. Literature Study, adalah proses mencari data pendukung yang didapatkan dari referensi berbagai sumber, baik dari segi akademis maupun non-akademis. Sumber tersebut antara lain berupa buku, jurnal, artikel, majalah, dan website. Literature Study dilakukan secara bersamaan dengan Survey.

d. Desain, adalah proses perancangan konsep desain yang menghasilkan sketsa gagasan/ide tentang perhiasan yang sesuai dengan hasil survey dan peluang pasar yang dikembangkan.

e. Development, adalah proses pengembangan desain yang terpilih untuk direalisasikan dalam sebuah prototipe dan dilakukan penyempurnaan sampai dapat diluncurkan ke tengah masyarakat.

\section{Hasil dan Pembahasan}

Discovery. Tahap discovery diawali dengan mengunjungi perusahaan emas terkait yang berlokasi di Surabaya untuk melakukan diskusi tentang peluang pasar yang dapat diekspose untuk lebih dikembangkan dan diwujudkan dalam bentuk prototipe. Peluang pasar yang dimaksud melingkupi desain perhiasan yang seperti apa yang biasa dibeli oleh personal atau user seperti bagaimana dan di mana perhiasan tersebut akan dipasarkan. Selain itu diskusi juga melingkupi penjelasan perusahaan tentang sistematika dalam proses pembuatan suatu perhiasan dari awal desain hingga siap dipasarkan. Langkah berikutnya adalah mengunjungi pameran perhiasan yang ada di Surabaya dan berbagai toko perhiasan emas untuk mengamati perhiasan yang ada di pasar saat ini, serta melakukan pengamatan perhiasan yang dikenakan oleh para wanita, baik di kantor, mall dan di beberapa tempat lain.

Survey. Pengamatan juga dilakukan dalam bentuk user diary. Dari peluang pasar yang diberikan oleh perusahaan, penulis dapat mencari dan melakukan pengamatan selama 7 hari tentang kegiatan user yang mendekati persona. Dari hasil survey dan pengamatan baik secara langsung maupun tidak (dengan melakukan user diary), diperoleh sebuah user insight yang mengerucut pada target user yang akan dituju, yaitu wanita berusia di atas 35 tahun, berdomisili di kota besar dan kota yang memiliki sektor industri dan 
populasi yang tinggi, berprofesi sebagai ibu rumah tangga, karyawan swasta, atau entrepreneur, memiliki penghasilan lebih dari 5 juta rupiah per bulan, dan merupakan pribadi yang gemar melakukan kegiatan shopping, menyukai style glamour, aktif tampil dalam kegiatan formal maupun non-formal serta memperhatikan style dan fesyen. User insight tersebut sesuai dengan peluang pasar yang dituju yaitu perhiasan 2in1 dengan style glamour perhiasan Dubai style untuk digunakan dalam kegiatan formal maupun non-formal. Dalam situs vocabulary.com, disebutkan bahwa kata "glamour" mengacu pada pesona atau keindahan magis yang melekat pada seseorang atau objek (vocabulary.com, 2018). Perhiasan glamour memiliki daya tarik tertentu yang mendebarkan atau menarik.

Literature Study. Survey dilakukan secara bersamaan dengan pencarian data pendukung, baik dari segi akademis maupun non-akademis. Sumber tersebut antara lain berupa buku, jurnal, artikel, majalah, dan website untuk mencari informasi dan gambaran sebanyak-banyaknya terkait dengan desain yang akan dibuat serta melakukan diskusi dengan pihak-pihak yang berkompeten. Diskusi dilakukan dengan kepala bagian $R \& D$ dari perusahaan emas terkait dan pemilik salah satu toko perhiasan tentang desain yang digemari oleh pasar. Setelah semua informasi dan data terkumpul, barulah proses desain dan development dilakukan untuk menciptakan sebuah desain yang dapat diterima oleh target pasar.

Desain. Desain perhiasan yang dibuat berupa kalung, cincin, gelang dan brooch 2in1. Dalam tahap desain, dibuat beberapa alternative dan perpaduan antara sistem dengan model perhiasan atau sistem dan corak atau motif yang akan diterapkan. Dari konsep perhiasan Dubai style yang ditujukan, dikembangkan menjadi tema Arabian Night yang diambil dari salah salah satu karakter dari kisah dongeng popular yang berlatar belakang Timur Tengah.

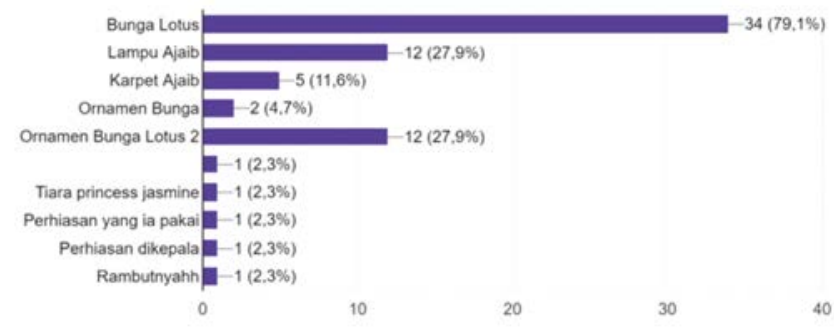

Gambar 1. Ringkasan hasil dari kuesioner (sumber: Ullah, 2019)

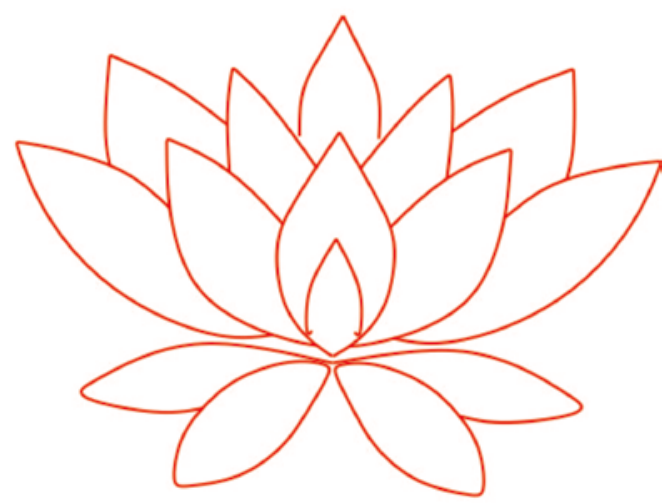

Gambar 2. Ikon bunga Lotus (sumber: Ullah, 2019)
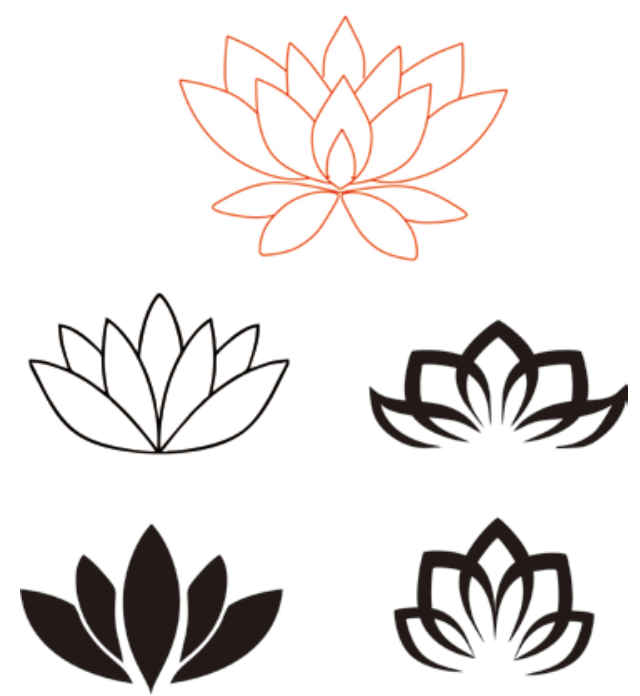

Gambar 3. Stilasi bunga Lotus (sumber: Ullah 2019)

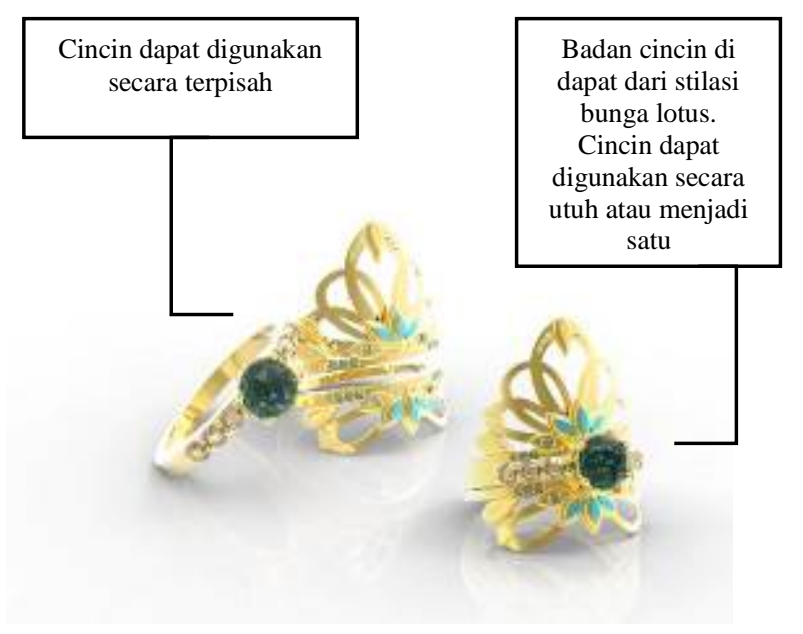

Gambar 4. Alternatif Desain 1 


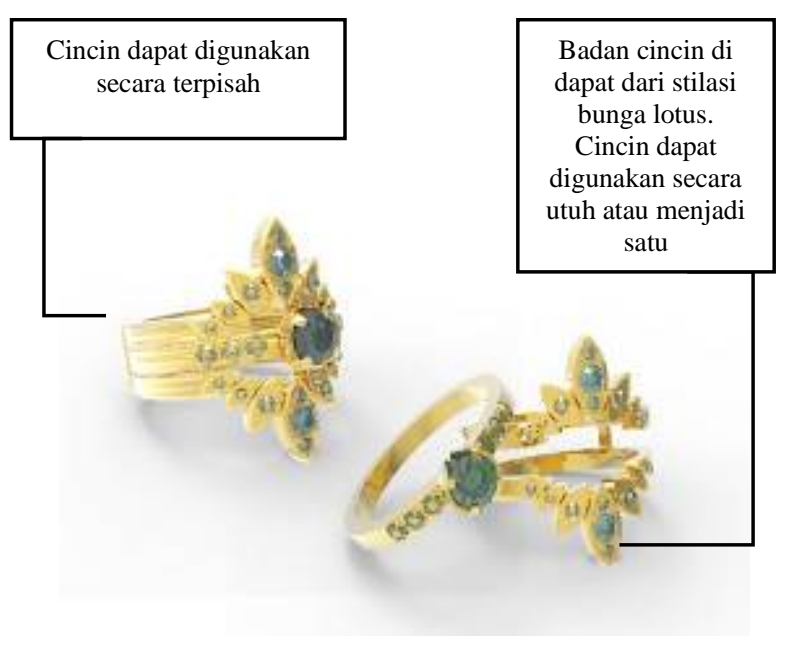

Gambar 5. Alternatif Desain 2
Alternatif desain dan stilasi motif corak dibuat dengan pertimbangan tertentu. Corak yang dipilih sebagai identitas dari series perhiasan yang akan dibuat adalah bunga lotus (Gambar 1) berdasarkan kuesioner yang telah disebarkan penulis pada 70 responden untuk mengetahui ikon yang paling menonjol dari cerita Arabian Night untuk perhiasan wanita. Bunga lotus sendiri juga mempunyai berbagai makna yang menggambarkan sisi feminim wanita.

Alternatif 1 (Gambar 2) dan 2 (Gambar 3) dari cincin yang merupakan perhiasan yang dikenakan pada jari, baik jari tangan atau kaki (Stuller, 2012). Cincin 2in1 berikut menggunakan sistem slip tanpa engsel, karena engsel akan menambah berat kotor gram perhiasan dan hanya dapat digunakan pada jari yang bersebelahan (contoh: jari manis dan jari tengah). Sistem slip membebaskan pengguna menggunakan cincin di jari mana saja.

Tabel 1. Alternatif sistem 2in1 pendant

\begin{tabular}{|c|c|c|c|}
\hline Alt & Ilustrasi & Kelebihan & Kekurangan \\
\hline 1 & & $\begin{array}{l}\text { Membentuk pendant } \\
\text { melingkar dan memanjang }\end{array}$ & $\begin{array}{l}\text { Konstruksi tiap bagian agar } \\
\text { saat ditutup dapat melingkar } \\
\text { dengan sempurna. }\end{array}$ \\
\hline 2 & & $\begin{array}{l}\text { Membentuk bentuk } \\
\text { lingkaran dan berubah } \\
\text { menjadi bentuk vertikal }\end{array}$ & $\begin{array}{l}\text { Menggunakan kuncian } \\
\text { magnet dan mudah aus atau } \\
\text { lecet. }\end{array}$ \\
\hline 3 & & $\begin{array}{l}\text { Pendant dapat dibuka dan } \\
\text { menjadi dua bagian yang } \\
\text { disatukan dengan magnet }\end{array}$ & $\begin{array}{l}\text { Kuncian dengan magnet } \\
\text { cepat mudah kehilangan } \\
\text { daya magnetnya. }\end{array}$ \\
\hline
\end{tabular}


Alternatif kalung sistem 2in1 yang dipilih adalah alternatif 1 yang menggunakan pendant dengan sistem yang tidak menambah berat gram dari perhiasan, mudah dibuka ditutup dan tidak mudah aus atau rusak karena sifat emas sendiri yang semakin lama akan semakin lunak (Tabel 1).

Alternatif 3 brooch 2in1 adalah alternatif yang paling mungkin digunakan karena tidak terlalu berat dan tidak menggunakan magnet untuk sistem kuncian. Brooch alternatif 3 juga dapat digunakan di bagian mana saja tanpa harus terbatas pada bagian dada (Tabel 2).
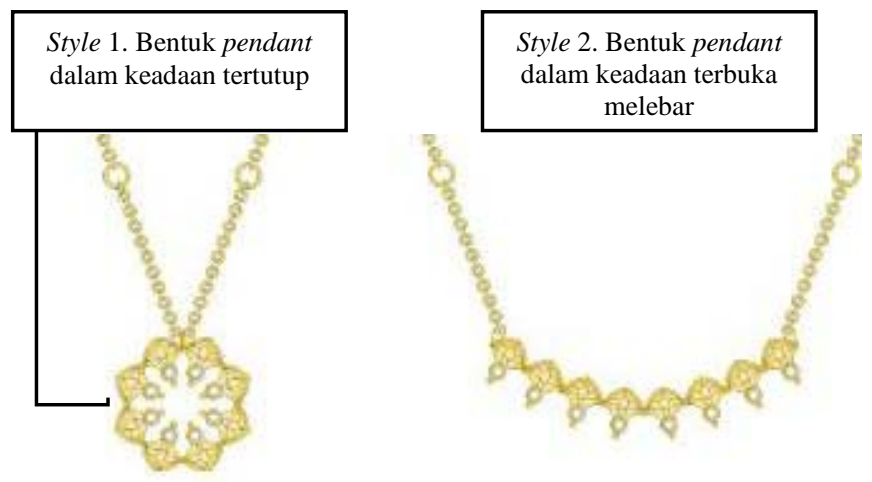

Gambar 9. Penyempurnaan alternatif 1 (sumber: PT UBS, 2019)

Tabel 2. Alternatif brooch sistem 2in1

\begin{tabular}{|c|c|c|c|}
\hline Alt & Ilustrasi & Kelebihan & Kekurangan \\
\hline 1 & & $\begin{array}{l}\text { Brooch dapat berubah } \\
\text { bentuk dari pendek menjadi } \\
\text { panjang }\end{array}$ & $\begin{array}{l}\text { Sistem kunciannya } \\
\text { menggunakan magnet }\end{array}$ \\
\hline 2 & & $\begin{array}{l}\text { Brooch dada klasik yang } \\
\text { dapat dipisah menjadi } \\
\text { Brooch dada dan bagian } \\
\text { rantai sebagai Brooch dagu } \\
\text { atau anting hijab. }\end{array}$ & $\begin{array}{l}\text { Ukuran Brooch dada yang } \\
\text { besar mempengaruhi berat } \\
\text { gram Brooch menjadi terlalu } \\
\text { besar dan berat. }\end{array}$ \\
\hline 3 & & $\begin{array}{l}\text { Brooch tusuk klasik yang } \\
\text { dapat dipisah menjadi } \\
\text { Brooch tusuk saja dan } \\
\text { gelang charm dari rantai } \\
\text { yang menggantung. }\end{array}$ & $\begin{array}{l}\text { Tusuk Brooch rawan } \\
\text { menekuk karena emas } \\
\text { adalah logam lunak. }\end{array}$ \\
\hline
\end{tabular}




\section{Kesimpulan}

Perhiasan 2in1 yang dapat diproduksi adalah perhiasan yang menggunakan sistem sederhana tanpa magnet sehingga tidak menambah berat perhiasan yang menjadi salah satu pertimbangan pengguna saat membeli perhiasan. Series perhiasan yang dibuat menggunakan nama lotus yang diambil dari motif stilasi dari bunga lotus dalam corak setiap perhiasan. Sistem yang diterapkan dalam cincin 2in1 lotus series adalah slip tanpa menggunakan engsel sehingga tidak menambah berat dari perhiasan.

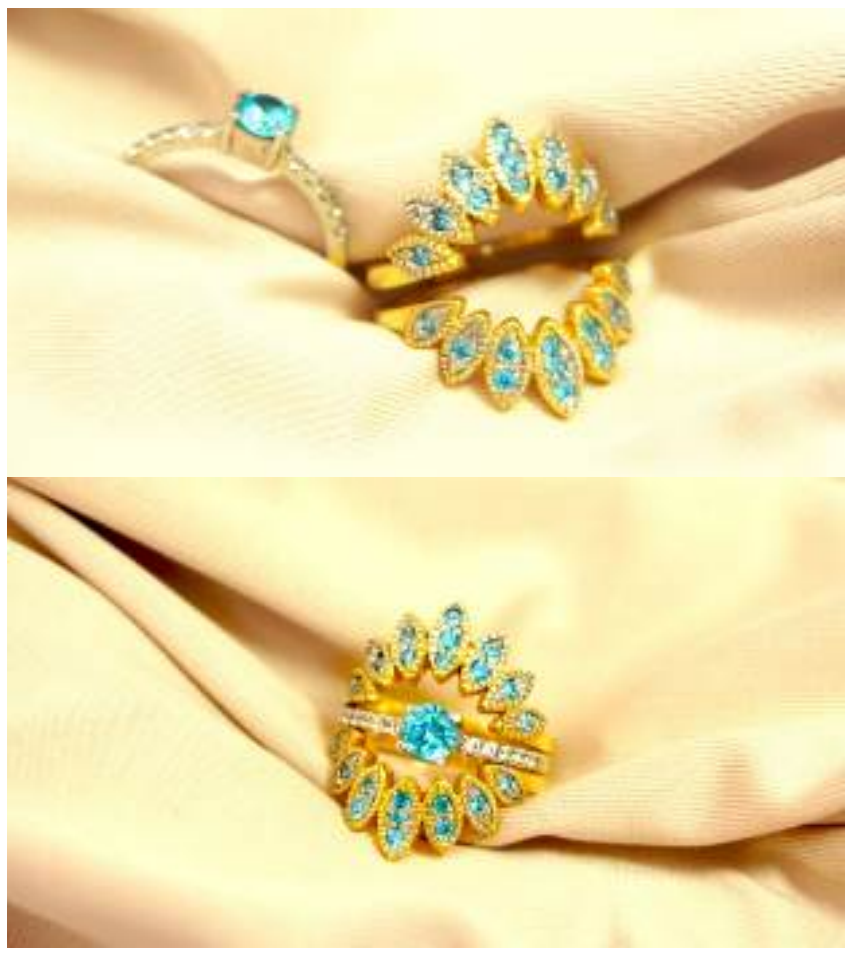

Gambar 10. Lotus 2in1 Ring terpisah (atas), Lotus 2in1 Ring tergabung

(sumber: dokumentasi penulis)

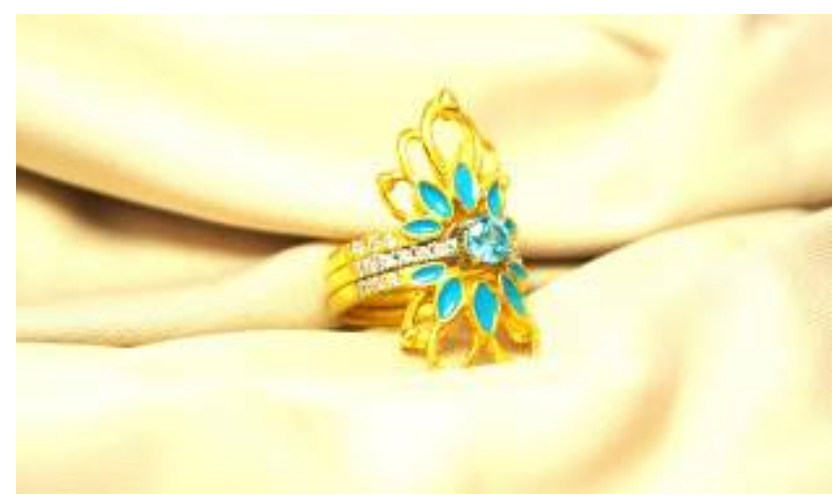

Gambar 11. Lotus Crown Ring Series (sumber: dokumentasi penulis)
Terdapat dua variasi warna batu yang digunakan dalam perhiasan ini. Batu yang digunakan adalah batu berwarna putih dan batu berwarna biru langit.
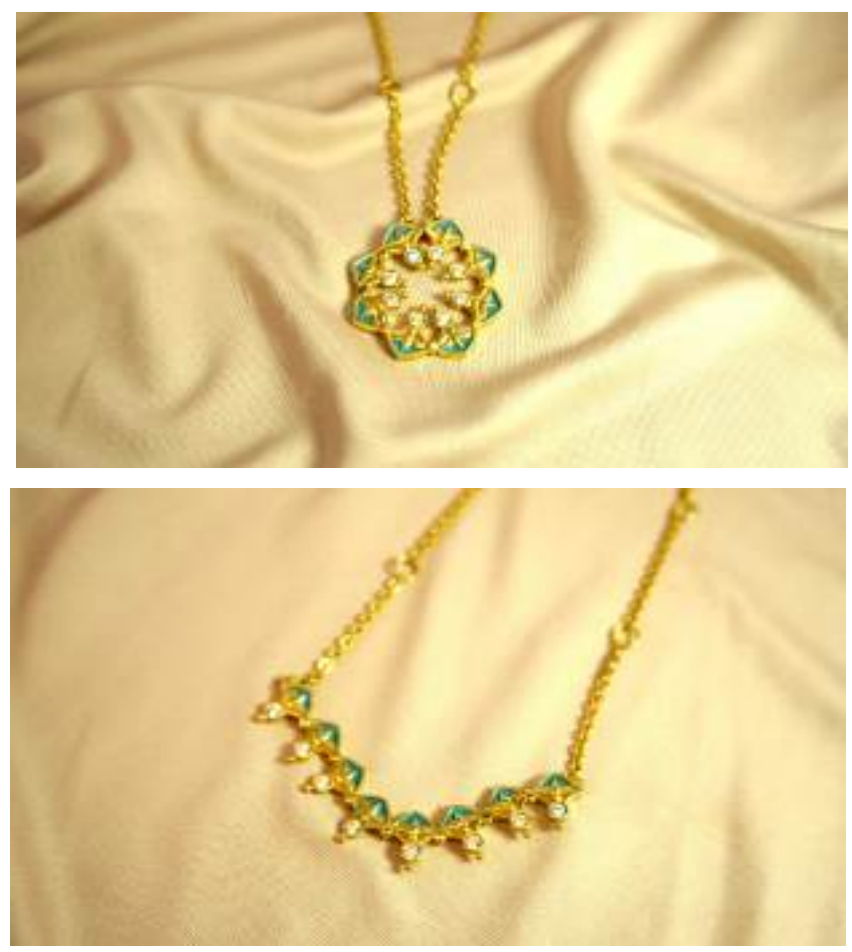

Gambar 12. Lotus petals neklace tertutup (atas), Lotus petals neklace terbuka (bawah) (sumber: dokumentasi penulis)

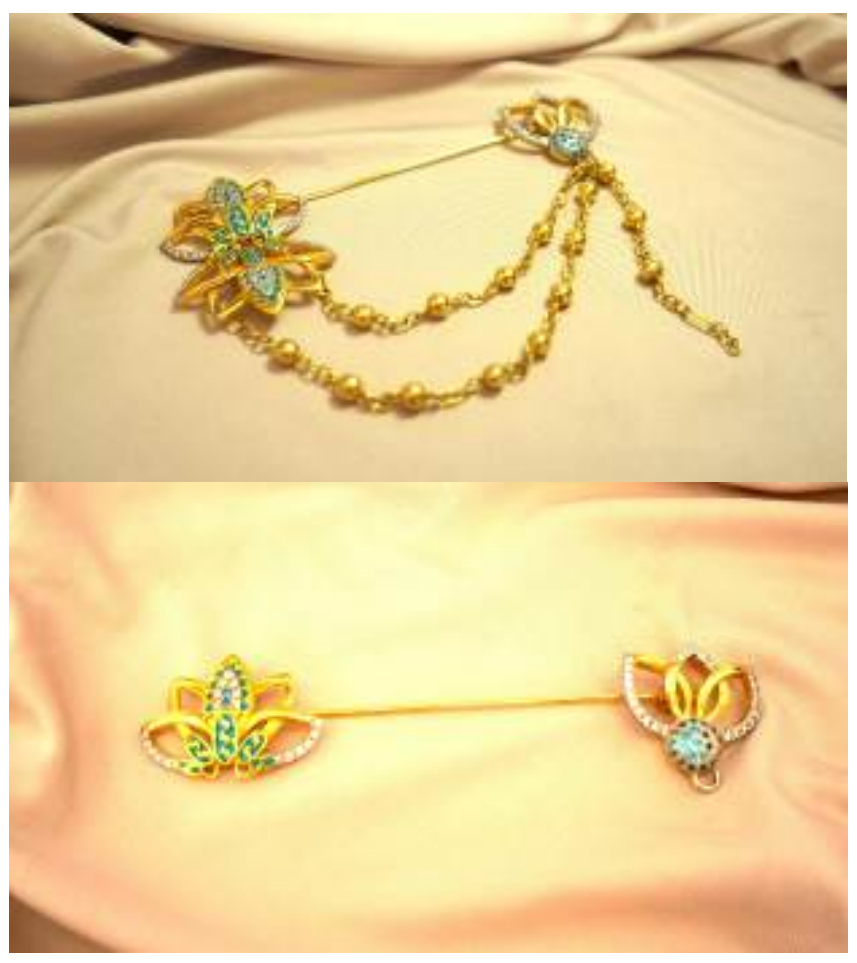

Gambar 13. Lotus 2in1 brooch (atas), Lotus 2in1 brooch, pin (sumber: dokumentasi penulis) 


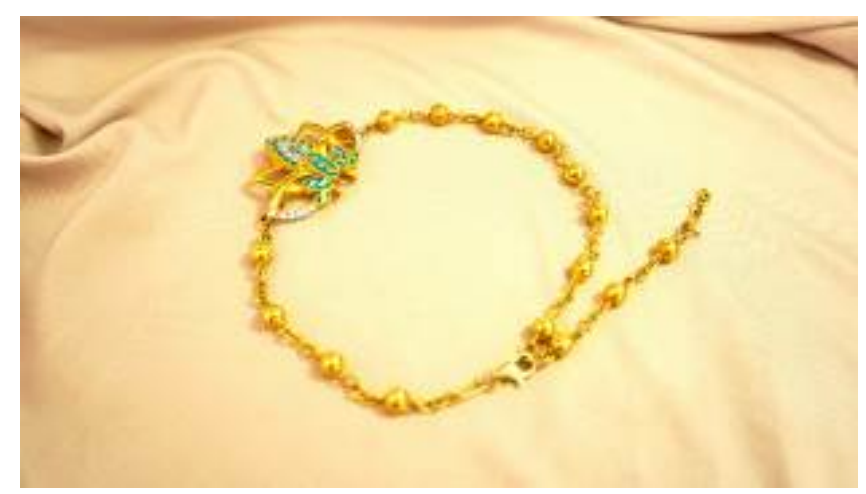

Gambar 14. 2in1 Lotus brooch, charm bracelet (sumber: dokumentasi penulis)

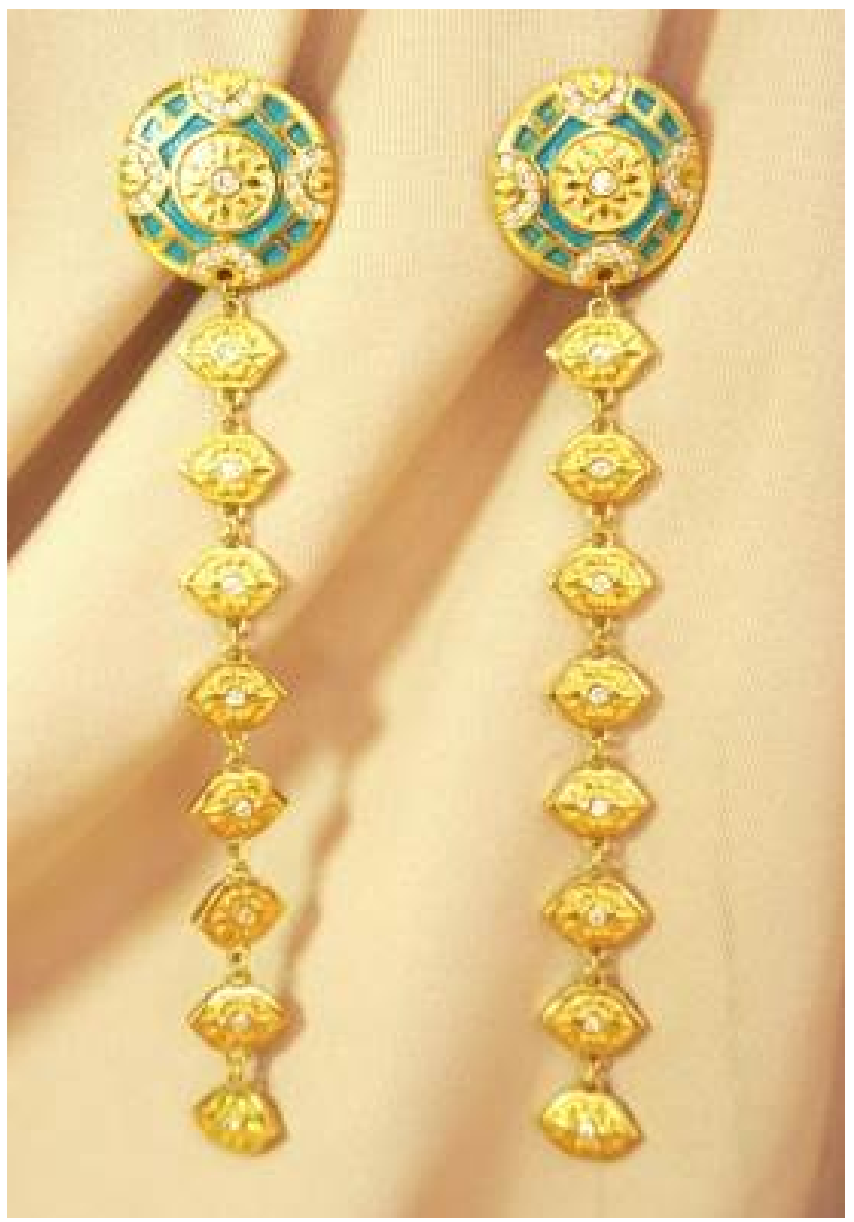

Gambar 15. Lotus petals earnings (sumber: dokumentasi penulis)

Panjang rantai produk perhiasan gelang tangan dirancang menyesuaikan lingkar tangan dengan ukuran $37 \mathrm{~cm}$. Dengan ukuran tersebut, diharapkan setiap wanita dapat menggunakannya dengan pas sesuai dengan ukuran pergelangan tangan yang kecil atau yang besar. Gambar 14 memperlihatkan produk 2in1 Lotus brooch dengan nama charm bracelet.

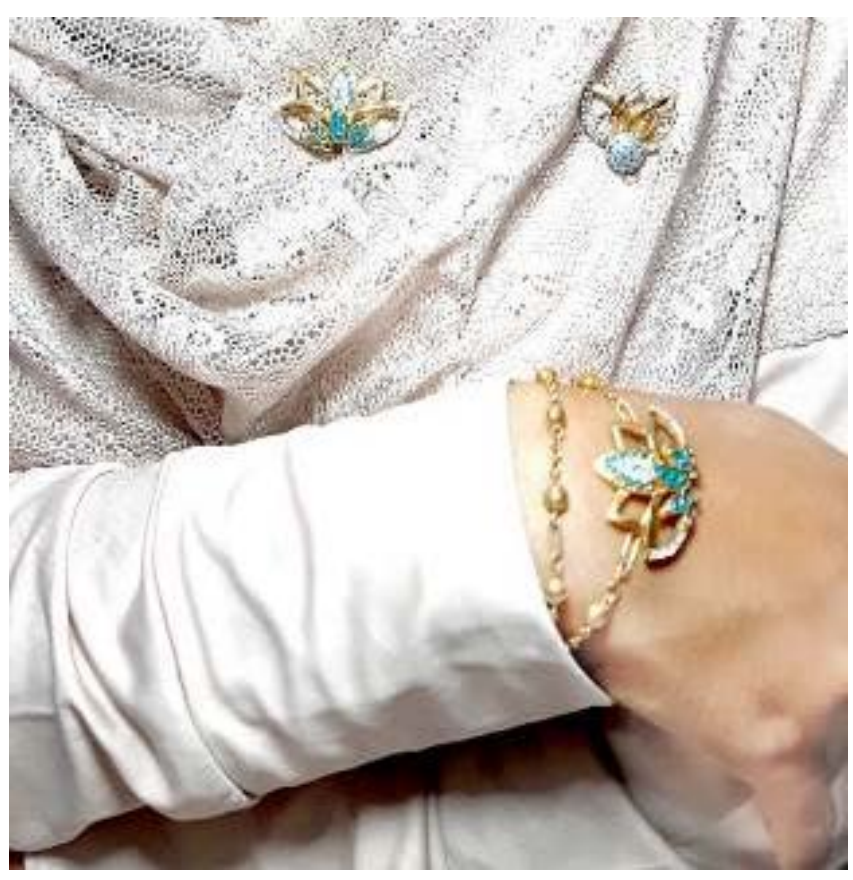

Gambar 16. Purwarupa 2in1 brooch Lotus Series (sumber: dokumentasi penulis)

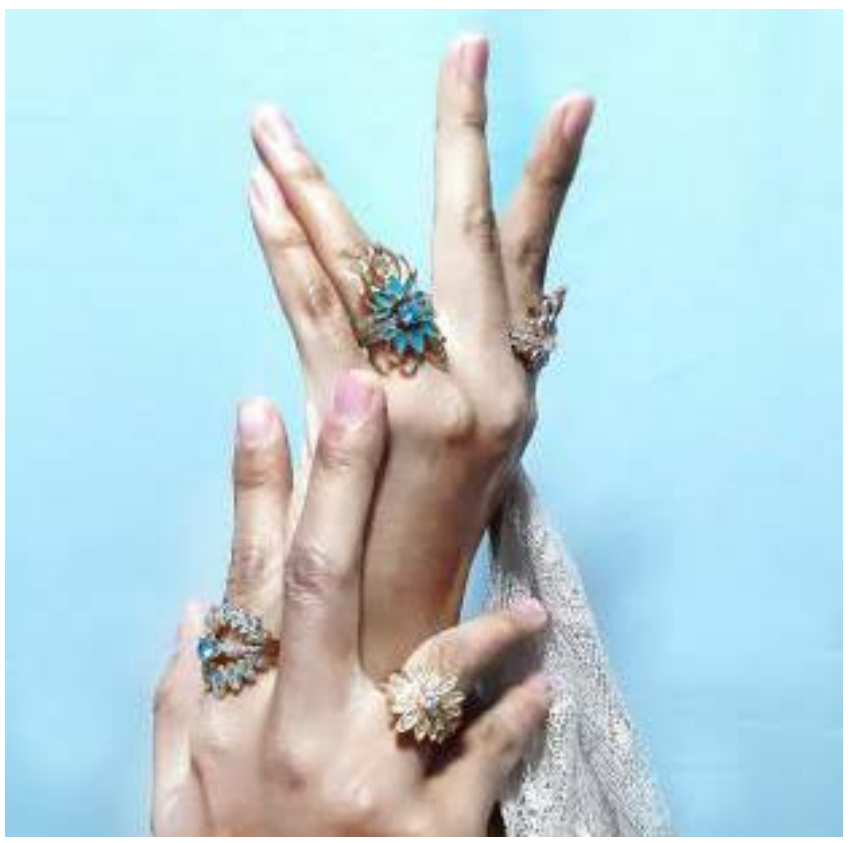

Gambar 17. Purwarupa 2in1 Ring Lotus Series (sumber: dokumentasi penulis)

Desain anting menjadi pelengkap set lotus series tanpa menggunakan sistem 2in1. Anting yang dibuat adalah stud earrings, sehingga pengguna hijab dapat menggunakan anting tersebut pada kerudungnya. Berat ideal untuk sepasang anting adalah kurang lebih 5 gram karena anting yang digunakan pada telinga tidak boleh menanggung berat yang berlebih agar tidak melukai pengguna (Gambar 15). 


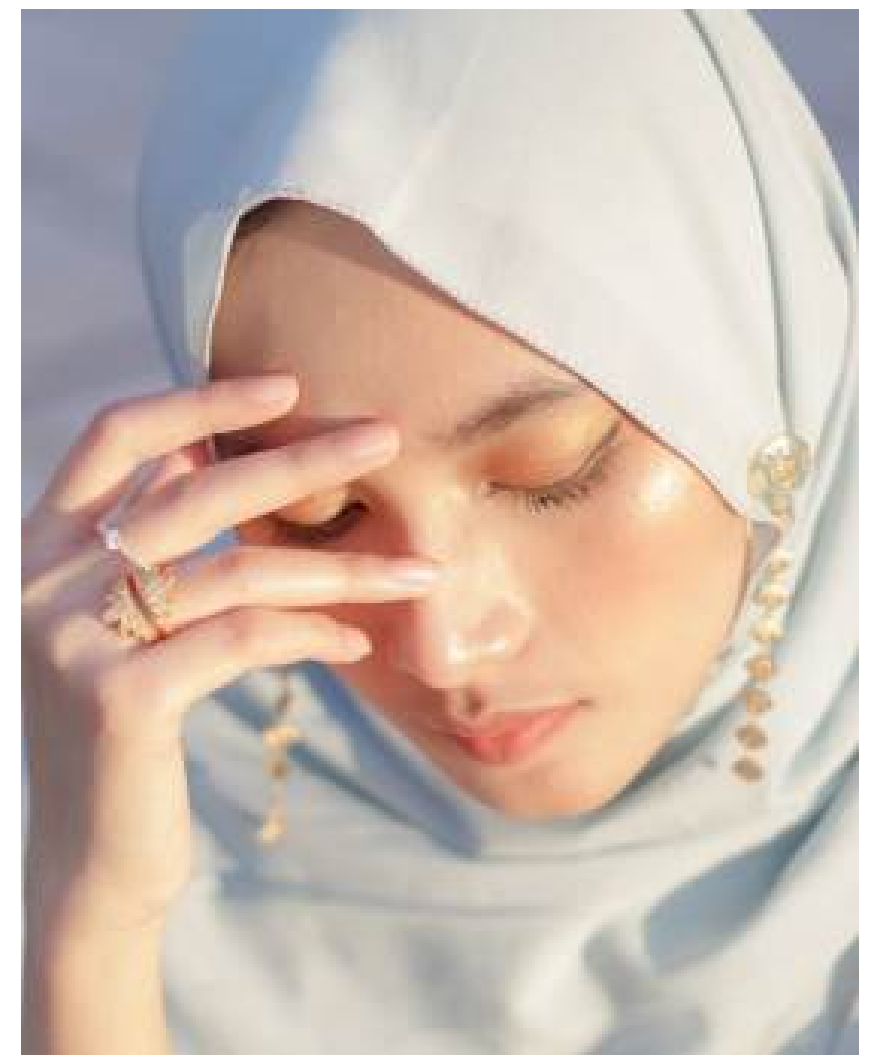

Gambar 17. Purwarupa 2in1 Lotus Series (sumber: dokumentasi penulis)

\section{Daftar pustaka}

bps.go.id. (2019) bps.go.id: statistik emas. Retrieved from bps.go.id: https://www.bps.go.id/statistikemas

Clarke, M. C. (2010). Oxford Concise Dictionary of Art Terms. British: Oxford University Press.

Flockinger, G. (2010). Foreword by Gerda Flockinger CBE. In C. Cor, Vintage Jewellery Collecting and Wearing TwentiethCentury Designs. London: Carlton Book.

Herdiana, W., \& Santoso, T. F. (2018). Perancangan Souvenir Beridentitas Tradisi Telingaan Aruu Khas Suku Dayak. Mudra Jurnal Seni Budaya, 33(2), 256-262.

kamuslengkap.com (2019) kamuslengkap.com: dictionary: two in one. Retrieved from kamuslengkap.com: https://www.kamuslengkap.com/dictionary/twoinone

Lignel, Benjamin. (2008). Critical Thinking: What does Contemporary Jewellery mean? Retrieved from https://klimt02.net/forum/articles/what-does contemporaryjewellery-meangbenjamin-lignel

Masmadia, A. S. (2018). Makna perhiasan emas bagi kalangan wanita Madura di Kota Surabaya. Jurnal S1-Sosiologi Fisip Universitas Airlangga. 1-16. Retrieved from http://repository.unair.ac.id/75114/3/JURNAL_Fis.S.50\%2018 \%20Mas\%20m.pdf

PT. UBS. (2019). UBSLifestyle. Retrieved from UBSLifestyle: https://ubslifestyle.com

Stuller. (2012). The Basic of Jewelry. Los Angeles: Stuller, Inc.

vocabulary.com. (2018). vocabulary.com: dictionary: glamour. Retrieved

from https://www.vocabulary.com/dictionary/glamour 